\title{
Process Development for Selective Laser Melting of Molybdenum
}

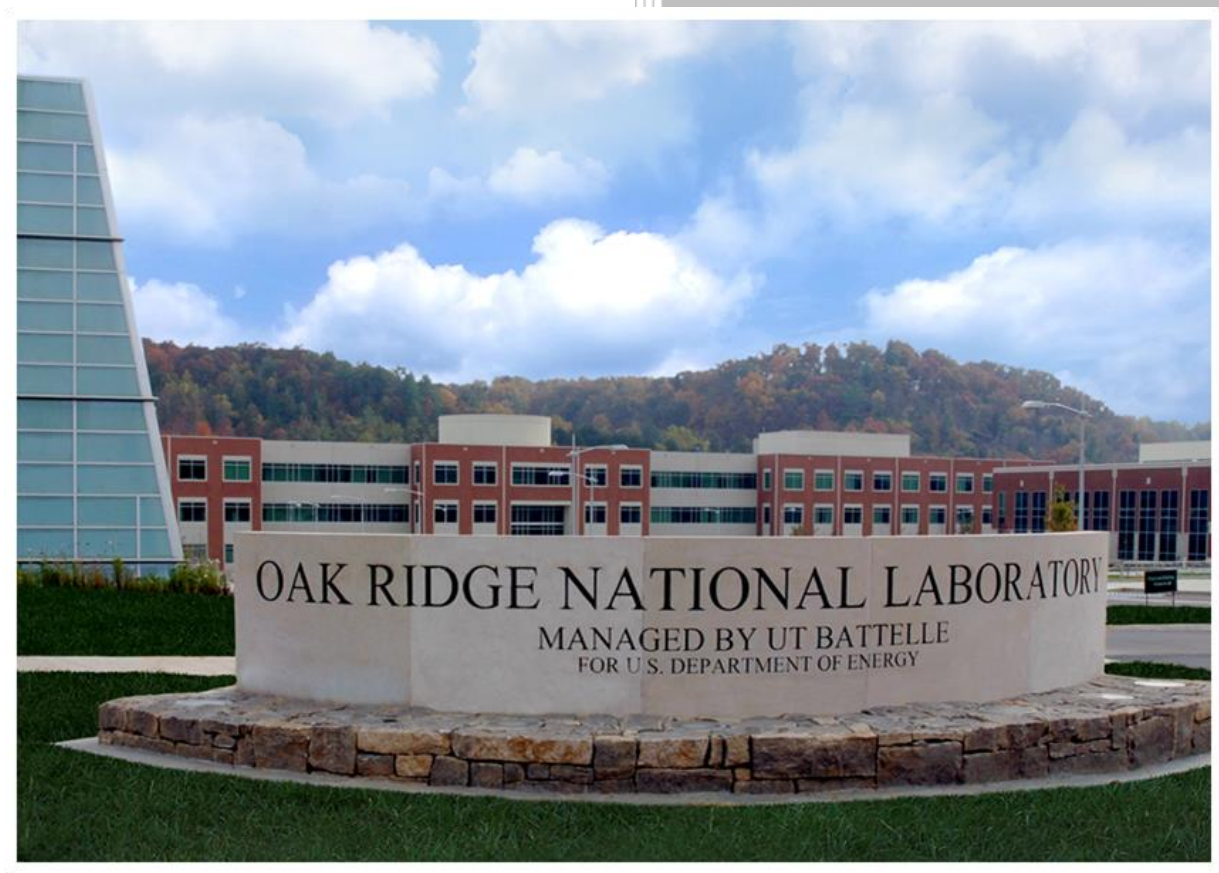

Brian T. Gibson

Richard A. Lowden

October 2018 


\title{
DOCUMENT AVAILABILITY
}

Reports produced after January 1, 1996, are generally available free via US Department of Energy (DOE) SciTech Connect.

Website www.osti.gov

Reports produced before January 1, 1996, may be purchased by members of the public from the following source:

\author{
National Technical Information Service \\ 5285 Port Royal Road \\ Springfield, VA 22161 \\ Telephone 703-605-6000 (1-800-553-6847) \\ TDD 703-487-4639 \\ Fax 703-605-6900 \\ E-mail info@ntis.gov \\ Website http://classic.ntis.gov/
}

Reports are available to DOE employees, DOE contractors, Energy Technology Data Exchange representatives, and International Nuclear Information System representatives from the following source:

Office of Scientific and Technical Information

PO Box 62

Oak Ridge, TN 37831

Telephone 865-576-8401

Fax 865-576-5728

E-mail reports@osti.gov

Website http://www.osti.gov/contact.html

This report was prepared as an account of work sponsored by an agency of the United States Government. Neither the United States Government nor any agency thereof, nor any of their employees, makes any warranty, express or implied, or assumes any legal liability or responsibility for the accuracy, completeness, or usefulness of any information, apparatus, product, or process disclosed, or represents that its use would not infringe privately owned rights. Reference herein to any specific commercial product, process, or service by trade name, trademark, manufacturer, or otherwise, does not necessarily constitute or imply its endorsement, recommendation, or favoring by the United States Government or any agency thereof. The views and opinions of authors expressed herein do not necessarily state or reflect those of the United States Government or any agency thereof. 


\title{
PROCESS DEVELOPMENT FOR SELECTIVE LASER MELTING OF MOLYBDENUM
}

\author{
Brian T. Gibson, Richard A. Lowden \\ Oak Ridge National Laboratory
}

October 2018

Prepared by

OAK RIDGE NATIONAL LABORATORY

Oak Ridge, TN 37831-6283

managed by

UT-BATTELLE, LLC

for the

US DEPARTMENT OF ENERGY

under contract DE-AC05-00OR22725 


\section{ABSTRACT}

This report presents a process development effort aimed at both identifying operating parameters for producing high quality Molybdenum components via Selective Laser Melting (SLM) and developing a framework for understanding parameter interactions and enabling informed decisionmaking in parameter selection. At the core of this effort was mapping of SLM process inputs to build outcomes, for which there are applicationbased constraints, e.g. final part density, surface finish, and dimensional accuracy. Process mapping in additive manufacturing is currently the subject of intense research efforts at many institutions, both experimentally and through computational modeling; this was an experimentally driven research effort, which was carried out with an understanding of the importance of the underlying mechanisms that are inherent to the SLM process, such as the impact of laser power and scan speed on melt pool morphology, as well as solidification dynamics. Results revealed promising avenues for mapping of SLM process parameters for Molybdenum and quantitatively reinforced ideas derived from observations of part quality, i.e. density, mass, surface roughness. 


\section{ACKNOWLEDGEMENTS}

Support was provided by the Department of Energy's National Nuclear Security Administration (DOE/NNSA), Office of Material Management and Minimization's Molybdenum-99 Program. The authors also gratefully acknowledge the technical support of Rick R. Lowden, Makayla Edwards, and Tracie Lowe of Oak Ridge National Laboratory. 


\section{CONTENTS}

Page

ABSTRACT …

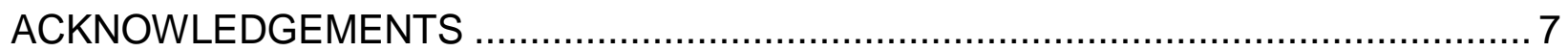

Section

1. INTRODUCTION

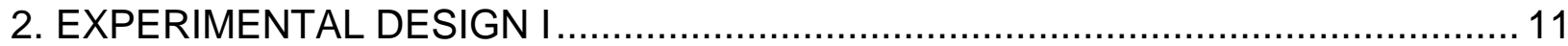

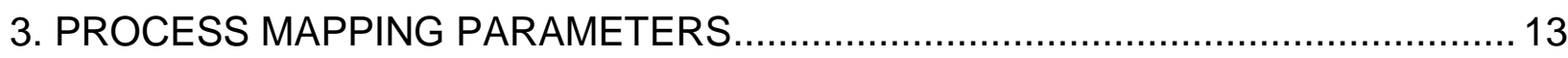

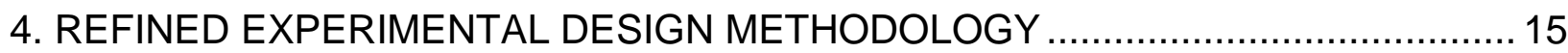

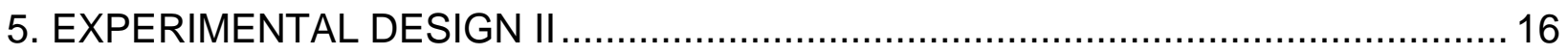

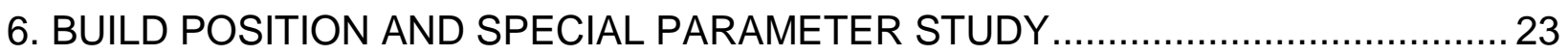

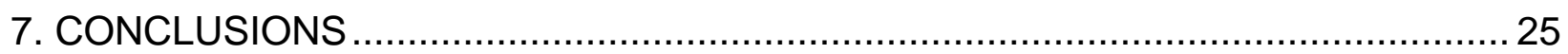

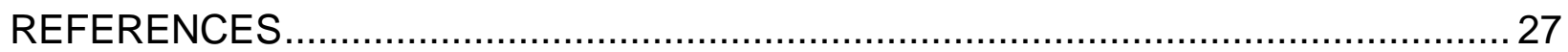

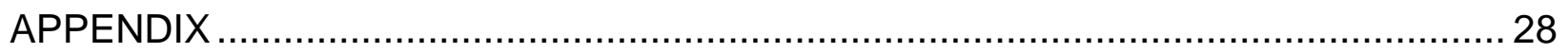




\section{PROCESS DEVELOPMENT FOR SELECTIVE LASER MELTING OF MOLYBDENUM}

\section{INTRODUCTION}

The overarching goal of this work was to develop a framework for making decisions about operating parameters in Selective Laser Melting (SLM) of Molybdenum. Generally, this meant attempting to map process inputs to build outcomes, for which there are application-based constraints, e.g. final part density, surface finish, and dimensional accuracy. Process mapping in additive manufacturing is currently the subject of intense research efforts at many institutions, both experimentally and through computational modeling; ref [1] provides just one significant example. This effort was experimental, and it was carried out with an understanding of the importance of the underlying mechanisms that are inherent to the SLM process, such as changes in size and shape of the melt pool with laser power and scan speed, as well as solidification dynamics.

\section{EXPERIMENTAL DESIGN I}

Experimental Design 1 established a basis for SLM of Molybdenum on the Renishaw AM400, with densities up to $95 \%$ achieved. This experimental design focused on three primary process variables: point distance, hatch distance, and exposure time. Hatch distance and point distance are depicted in Figure 1.

\section{Point Distance}
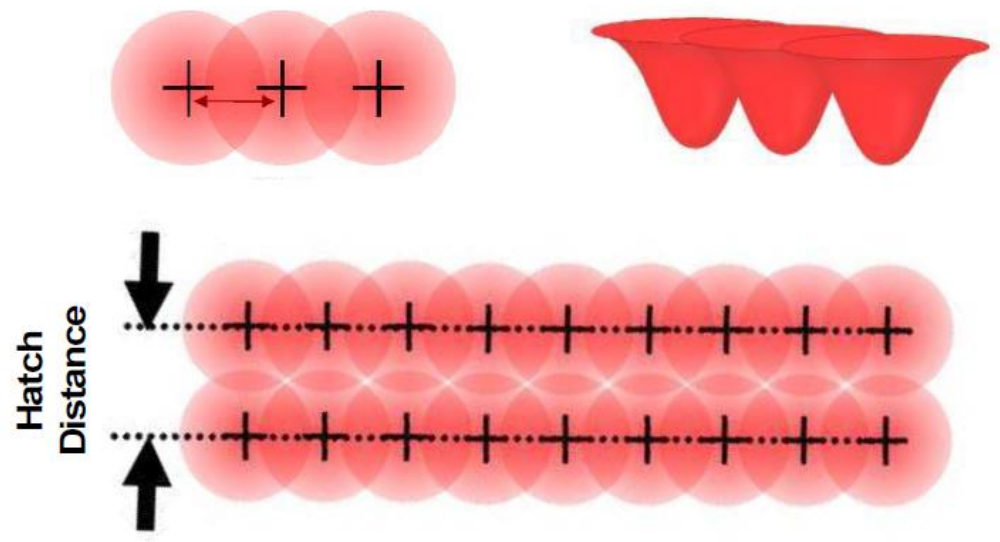

Figure 1: Point (or spot) Distance and Hatch Distance; Images Courtesy of Renishaw AMPD 


\section{Table 1: Experimental Design 1 Variables}

\section{- Independent Variables}

- Spot Distance: 50, 75 and $100 \mu \mathrm{m}$

- Hash Distance: 50, 75, and $100 \mu \mathrm{m}$

- Exposure time: 200, 300 and $400 \mu \mathrm{s}$

- Fixed

- Power: 400 watts

- Spot size: $150 \mu \mathrm{m}(130 \mu \mathrm{m})$

- Powder layer: $30 \mu \mathrm{m}$

- Particle size: $30 \pm 15 \mu \mathrm{m}$ (TEKNA Mo45)

- Dependent Variables

- Density (88 to $95 \%$ )

- Open porosity (4 to $\sim 10 \%$ )

- Thickness

- Weight

- Width

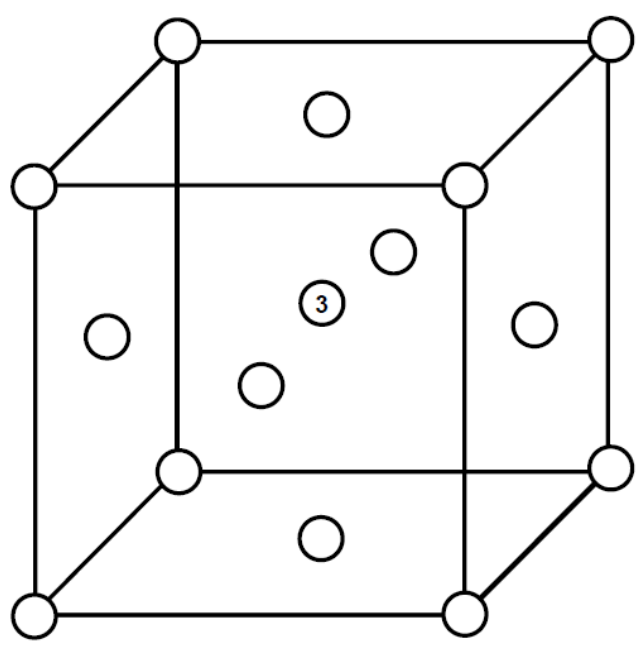

17 sets of independent variables including 3 repetitions of the center point

Test specimen: $10 \times 10 \mathrm{x} \sim 1 \mathrm{~mm}$ coupon

Table 1 lists all independent, constant, and dependent variables and the test specimen geometry for Experimental Design 1, along with results for density and open porosity. Density results, measured via immersion, for the various cases (parameter combinations) are plotted in Figure 2 and color coordinated according to build plate number.

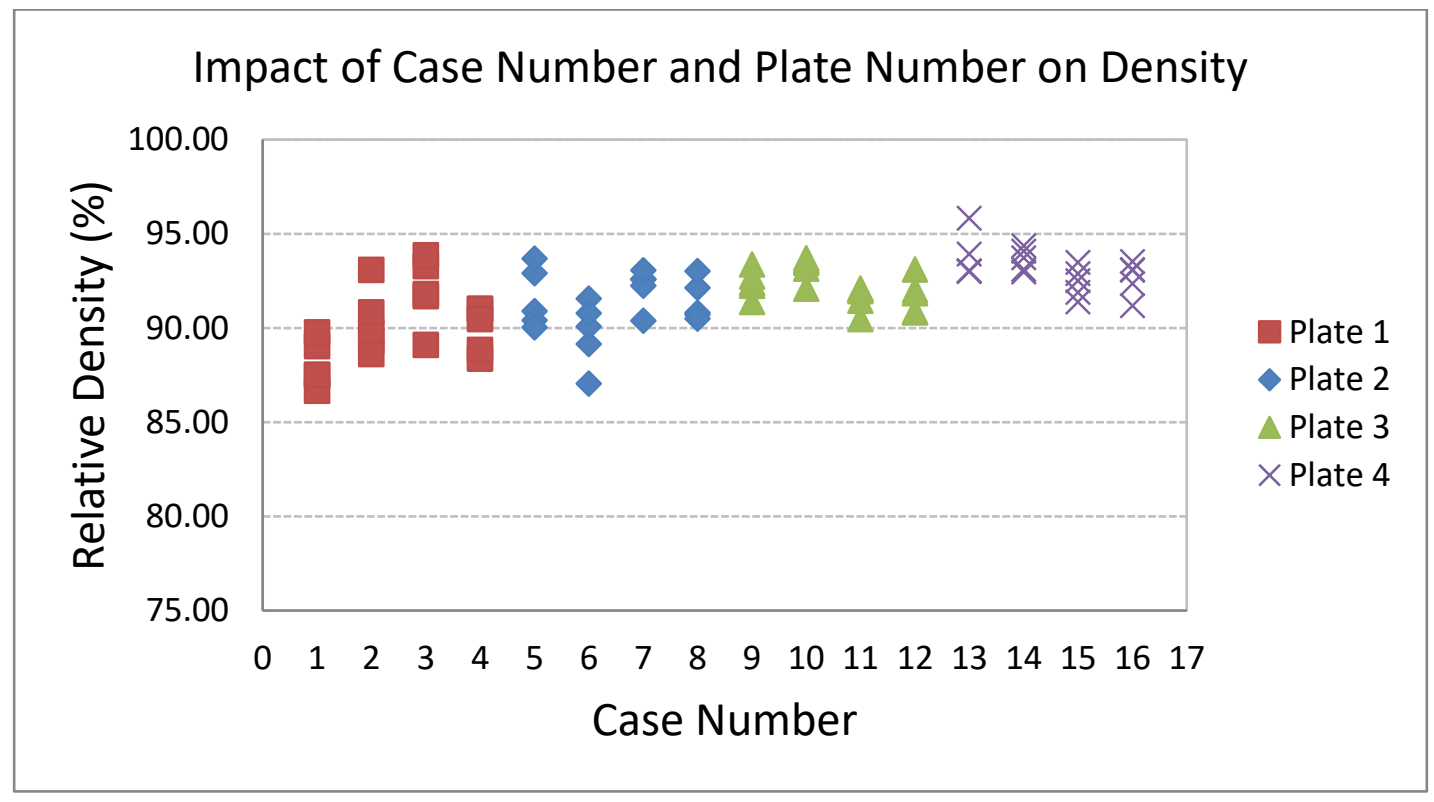

Figure 2: Density Results for Experimental Design 1 
A concern with the density results of Experimental Design 1, shown in Figure 2, is the way in which cases are distributed across the plates could have resulted in plate-to-plate variance amplifying the perceived case-to-case variation, e.g. the highest density cases seem to originate from Plate 4. However, the next effort was focused on identifying meaningful process parameters, against which build outcomes of density, open porosity, and mass for Experimental Design 1 would be plotted.

\section{PROCESS MAPPING PARAMETERS}

Laser Specific Energy (LSE), or energy input per volume of build, and scan speed emerged as candidate parameters for mapping; there is also a basis in the literature for mapping with these parameters for SLM of Titanium [2]. These parameters can be nondimensionalized using material and process properties, which would allow for mapping outcomes to be translated across alloy systems [3]; scan speed can be nondimensionalized to become a form of the Peclet Number. Because the Renishaw AM400 operates with discrete laser spot exposures, an analogous scan speed was computed based on the exposure time, spot spacing, jump speed, and jump delay time. Equations for these parameters are shown below:

$$
\text { Laser Specific Energy, } \boldsymbol{E}_{\boldsymbol{V}}=\frac{\text { Laser Power } \times \text { Exposure Time }}{\text { Layer Thickness } \times \text { Hatch Distance } \times \text { Spot Distance }}
$$$$
\text { Scan Speed }=\frac{\text { Spot Distance }}{\text { Exposure Time }+ \text { Point Jump Time }+ \text { Jump Delay Time }}
$$$$
\text { Point Jump Time }=\frac{\text { Spot Distance }}{\text { Point Jump Speed }} \quad \begin{gathered}
\text { 'For the RenighnwaMm } 400 \\
\text { Point Jump Speed }=5000 \text { mm/s } \\
\text { Jump Delay Time }=0 \text { ms }
\end{gathered}
$$

Peclet Number $=\frac{\text { Scan Speed } \times \text { Spot Size }}{\text { Average Thermal Diffusivity }}$

Plotting Experimental Design 1 densities against these parameters yielded a very intriguing result, in which a clear trend was evident, shown in Figure 3. Microscopy also confirmed the differences in build quality that underlie the trend in density. Subsequent work would be aimed at replicating this trend. An additional interesting observation was the seemingly inverse relationship between mass and density for Experimental Design 1 data. Mass has been plotted against the same parameters as density in Figure 3 and the result is shown in Figure 4. The working hypothesis is that low densities can be driven, in part, by porous surface finishes that have additional powder bonded to the surface. 

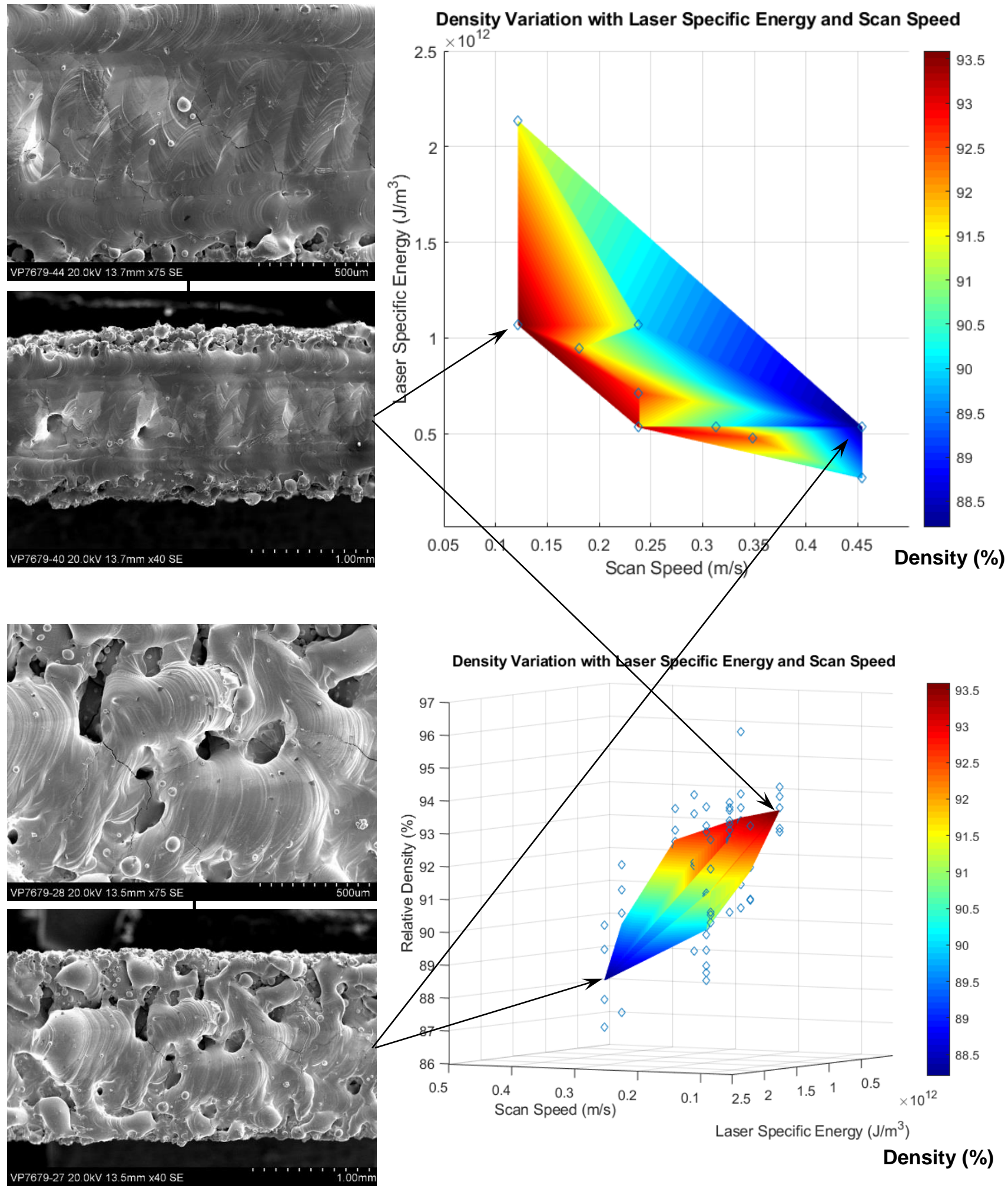

Density (\%)

Figure 3: Colormap of Density (\%) Variation with LSE and Scan Speed (Top-Right); Rotated Colormap of Same Data (Bottom-RIght); SEM Micrographs (Left) 


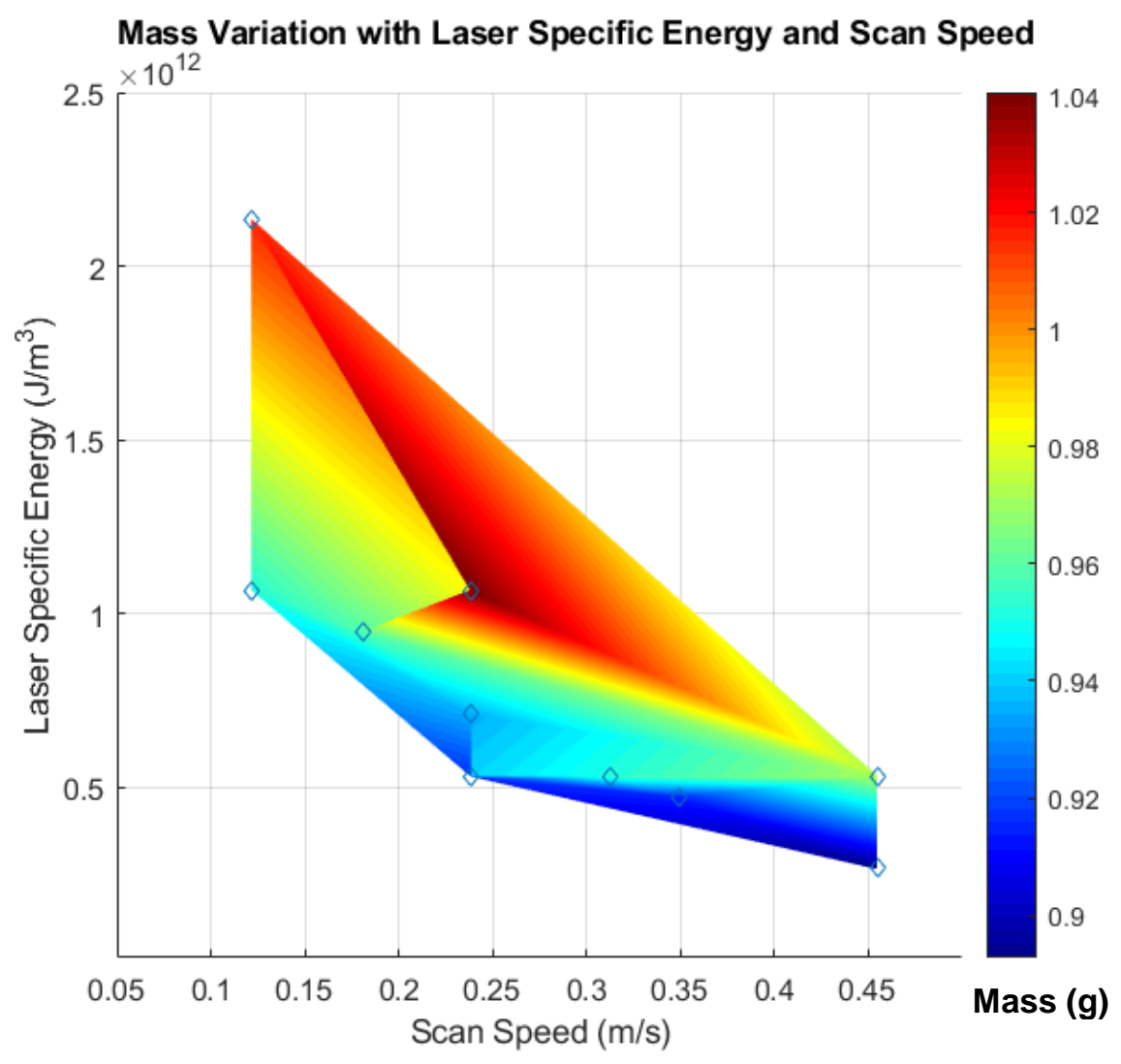

Figure 4: Colormap of Specimen Mass (g) Variation with LSE and Scan Speed; An Inverse Relationship with Density is Apparent in Comparison with Figure 3.

\section{REFINED EXPERIMENTAL DESIGN METHODOLOGY}

Following Experimental Design 1, a refined methodology was used for selecting the primary SLM operating parameters for subsequent experimental designs. Study of the process mapping parameters revealed that, given a laser power and a layer thickness, selecting a point on the LSE vs. Scan Speed plot automatically determines the hatch distance (this equation is shown in Figure 5). Thus, hatch distance can be plotted for a continuum of LSE and scan speed parameters, yielding a useful visualization for aiding in selecting operating parameters for experimental designs. Figure 5 shows such a plot, with the points of operation for Experimental Design 1 overlaid. In Experimental Design 1 , points of operation that yielded higher density specimens tended to be on the lower left of the plot, near the threshold of hatch distance equating to the laser spot size. This region became an increased area of interest for future studies. 

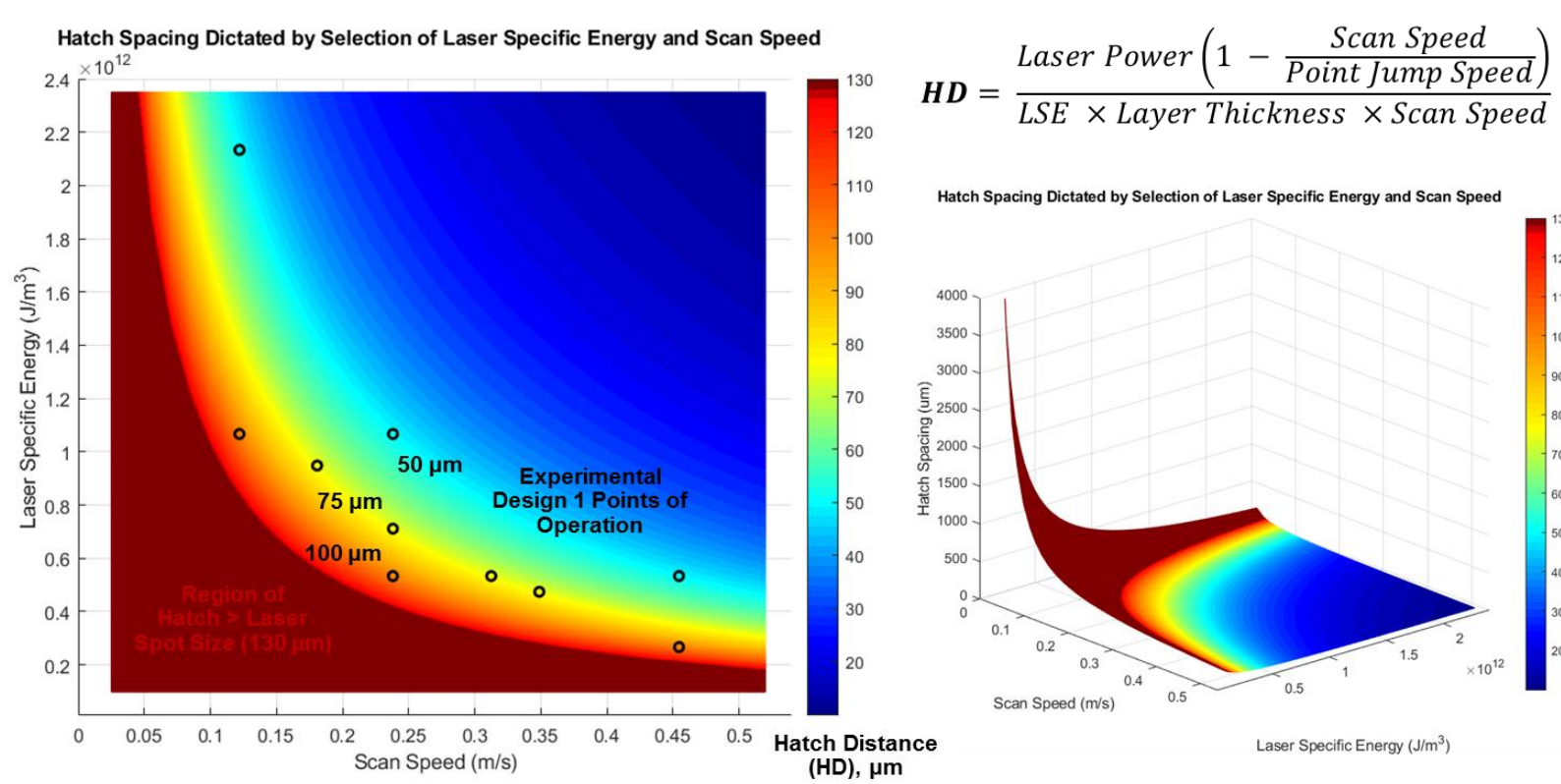

Hatch Spacing Dictated by Selection of Laser Specific Energy and Scan Speed

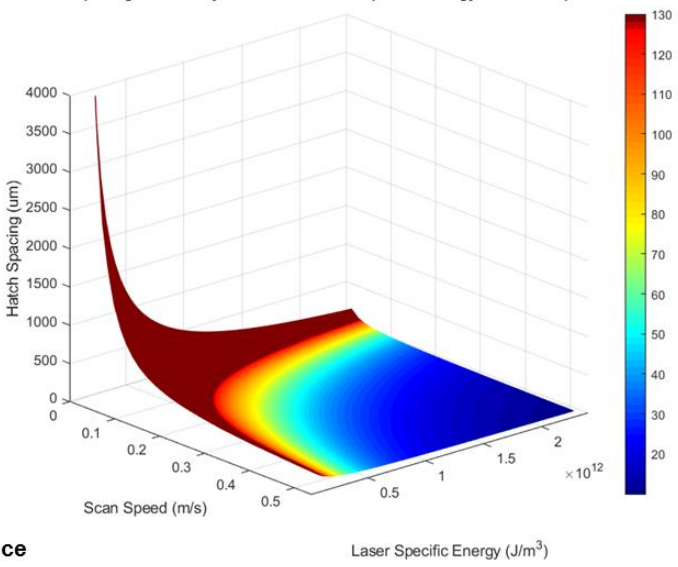

Figure 5: Colormap of Hatch Spacing as it Varies with Laser Specific Energy and Scan Speed; Overlaid with Experimental Design 1 Points of Operation (Left); Rotated Colormap of Same Data (Right)

\section{EXPERIMENTAL DESIGN II}

Experimental Design 2 objectives included replicating the trend that was evident in the map of density (laser specific energy vs. scan speed) for Experimental Design 1 data, to understand and operate within intuitive parameter limits, while also expanding the density map to both higher and lower density regions, and to understand changes in the Renishaw AM400 performance after issues with the laser (focus and cleanliness) were resolved following the execution of Experimental Design 1. In general, lower exposure times, e.g. $200 \mu \mathrm{s}$ instead of $400 \mu \mathrm{s}$, are now viewed as more favorable. As a result, exposure times for Experimental Design 2 were lowered, in comparison to those of Experimental Design 1. A study was designed using the refined experimental design methodology described in Section 4. A total of 12 cases (parameters combinations) were specified with 5 replicates of each case produced (a total of 60 test specimens spread over 3 build plates, identified as plates $7-9$ ). One of the primary differences between Experimental Designs 1 and 2 is that in Experimental Design 2, replicates of the cases were evenly distributed across all three build plates, in an attempt to distribute the variance, or noise, due to plate-to-plate differences evenly across all cases. Specimen geometry remained the same. Table 2 lists the operating parameters for Experimental Design 2. 
Table 2: Experimental Design II Parameters

\begin{tabular}{|c|c|c|c|}
\hline $\begin{array}{c}\text { Case } \\
\text { No. }\end{array}$ & $\begin{array}{c}\text { Time } \\
(\boldsymbol{\mu s})\end{array}$ & $\begin{array}{c}\text { Spot } \\
(\boldsymbol{\mu m})\end{array}$ & $\begin{array}{c}\text { Hatch } \\
(\boldsymbol{\mu m})\end{array}$ \\
\hline 13 & 200 & 34 & 110 \\
\hline 14 & 200 & 34 & 55 \\
\hline 15 & 200 & 50 & 110 \\
\hline 16 & 200 & 55 & 82 \\
\hline 17 & 200 & 55 & 46 \\
\hline 18 & 200 & 63 & 82 \\
\hline 19 & 200 & 75 & 110 \\
\hline 20 & 200 & 75 & 50 \\
\hline 21 & 200 & 75 & 25 \\
\hline 22 & 200 & 110 & 46 \\
\hline 23 & 200 & 110 & 55 \\
\hline 24 & 200 & 110 & 25 \\
\hline
\end{tabular}

Figure 6 displays the Experimental Design 2 cases on the hatch distance versus LSE and scan speed plot. Several cases have been intentionally concentrated in the lower region of the plot.

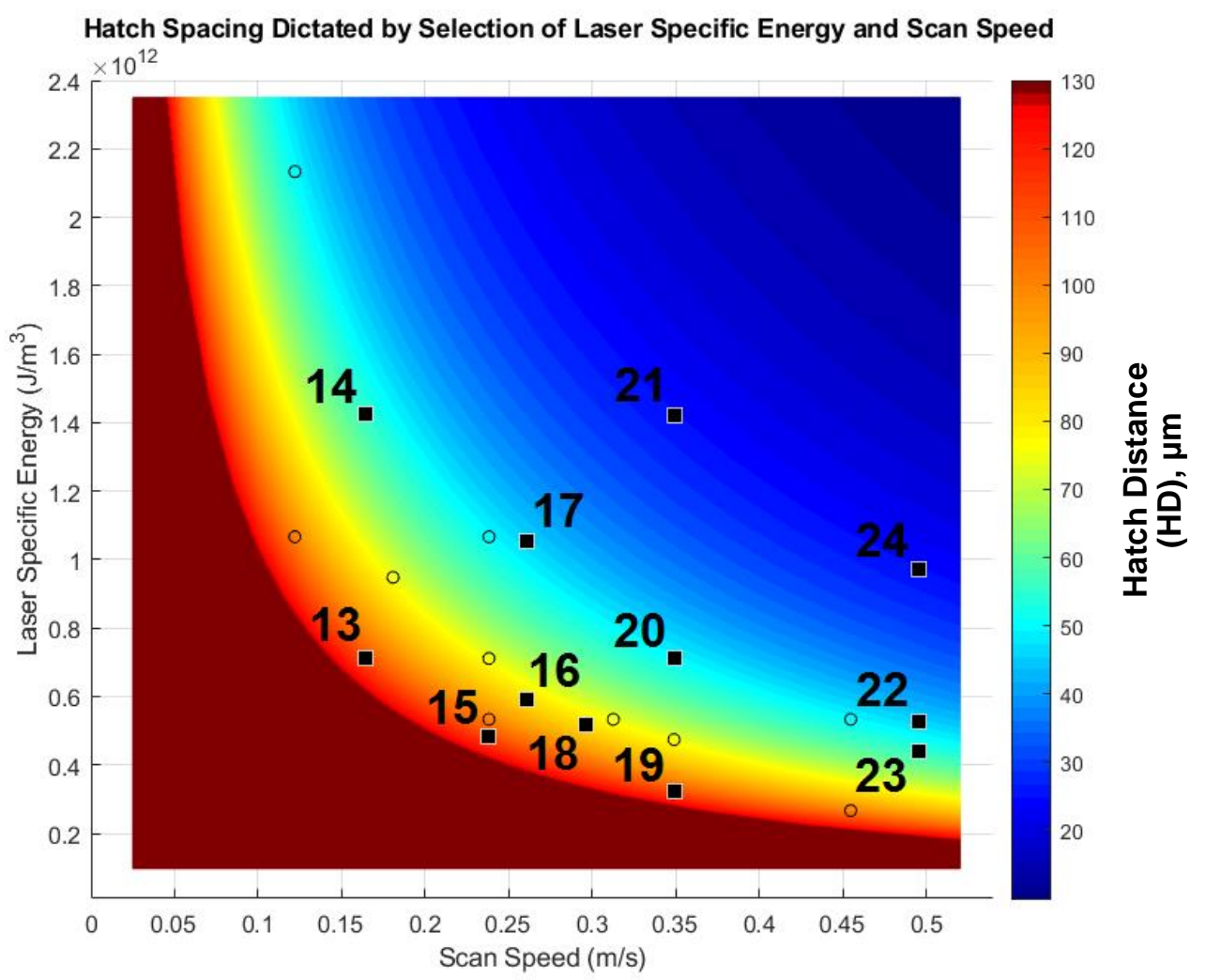

Figure 6: Experimental Design II Case Map 
Figure 7 displays an image of a completed build plate from Experimental Design 2, showing the skewed specimen build positions relative to the power recoating axis.

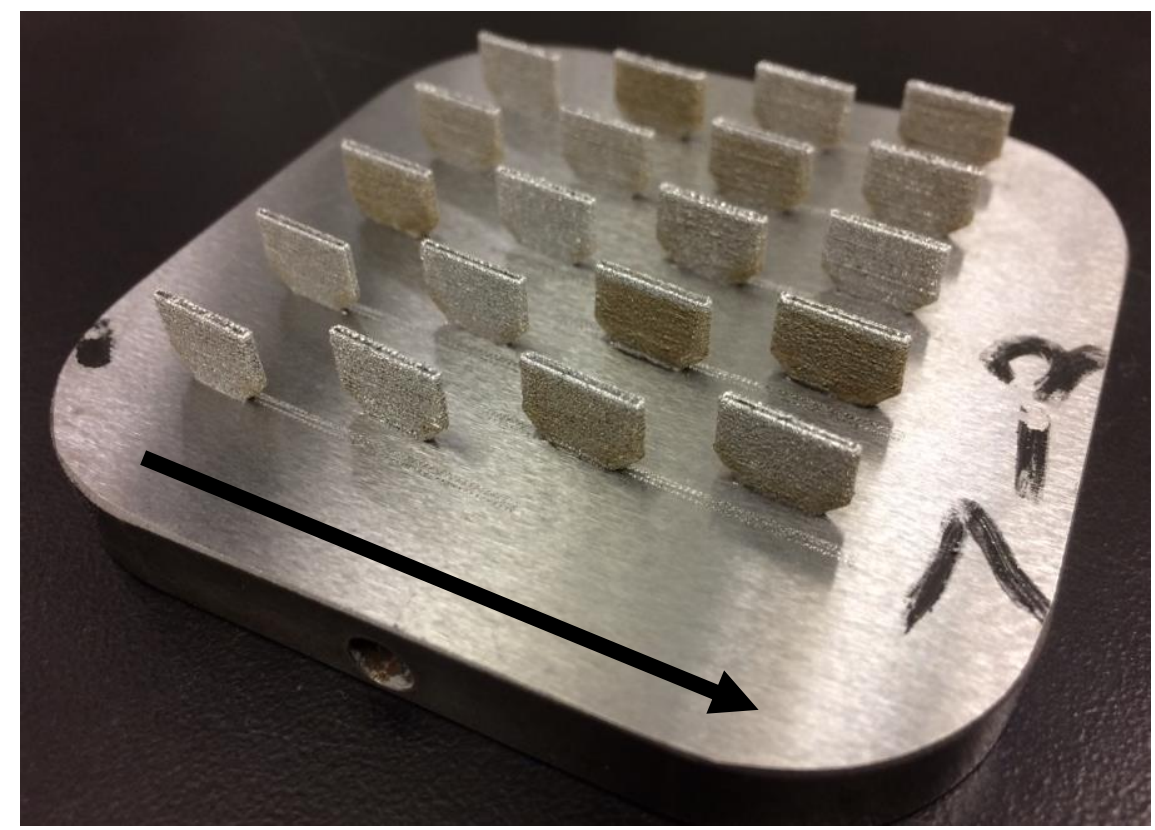

Figure 7: Build Plate from Experimental Design 2; Power Recoating Axis Indicated by Arrow

The density results for Experimental Design 2 are shown in Figure 8.

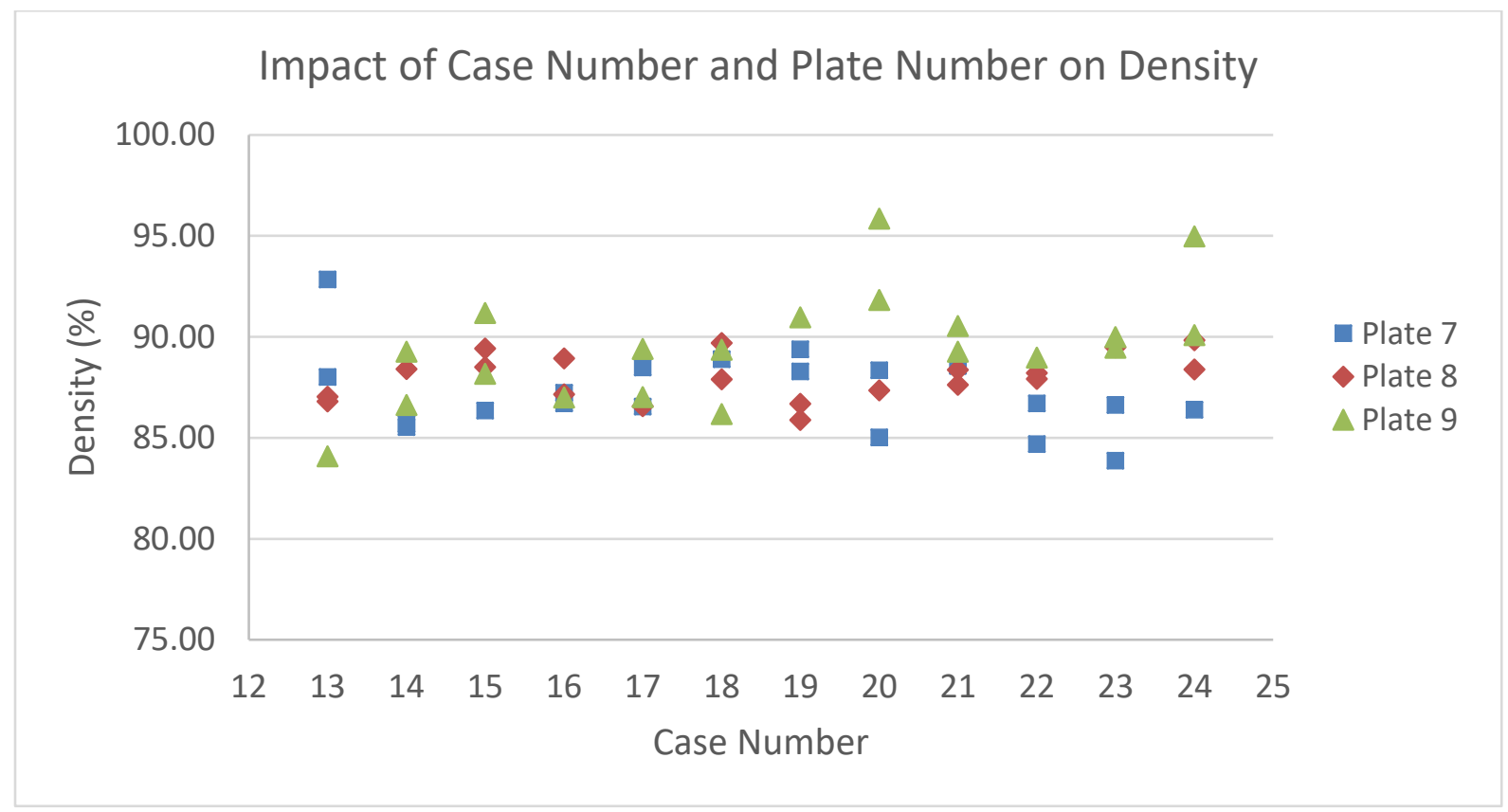

Figure 8: Density Results for Experimental Design 2 
Build position on the plate was also randomized for Experimental Design 2, meaning that variance due to both plate-to-plate effects and build position effects are 'built in' to the results. The effect of case on density is not apparent in Figure 8; the within-case density variance is larger than any apparent case-to-case differences in density. The results were plotted against LSE and scan speed and the results are shown in Figure 9, using the same color scale for density as that of Figure 3 to allow for direct comparisons of Experimental Design 1 and 2 data.

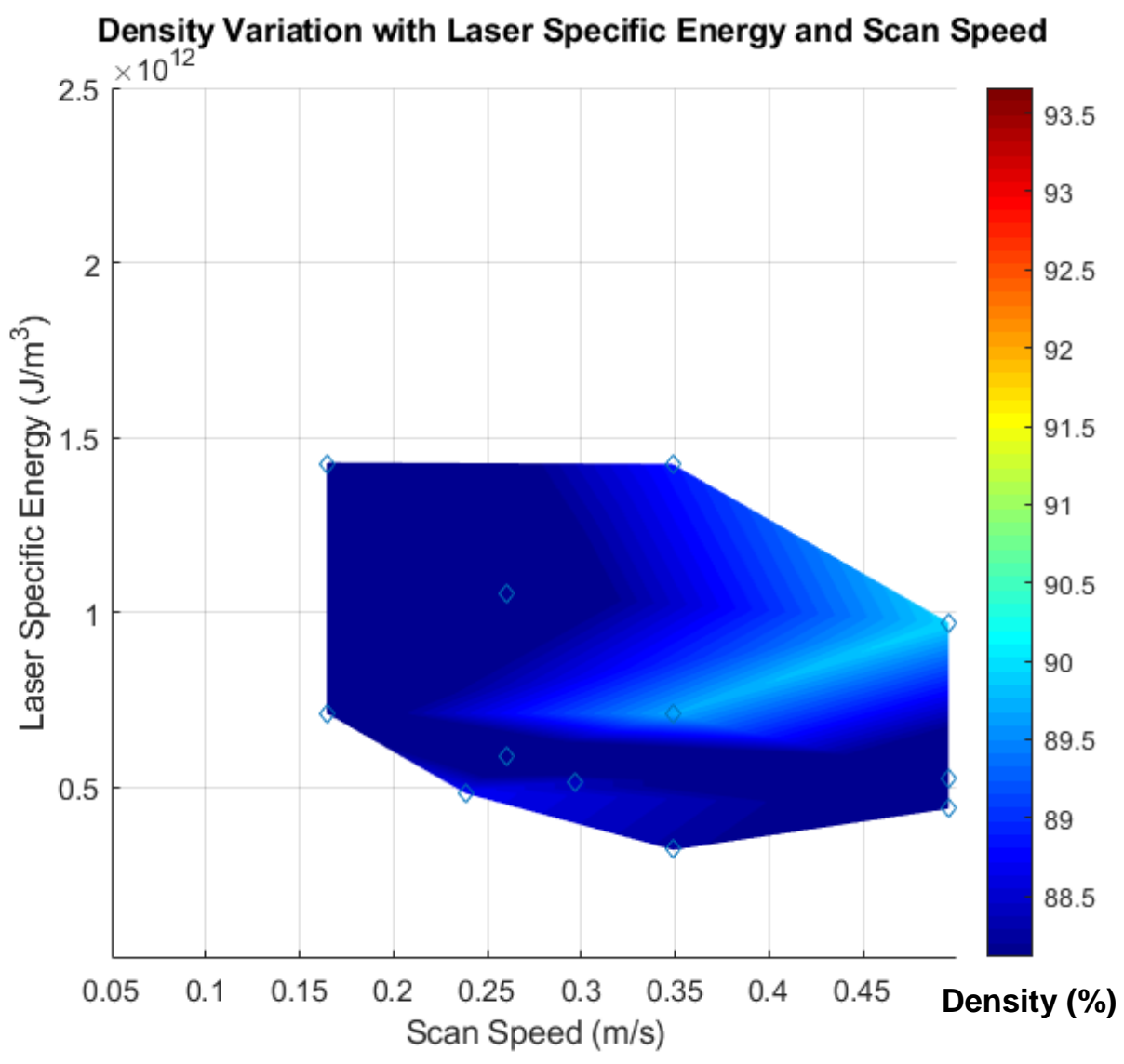

Figure 9: Density (\%) Results for Experimental Design 2, Plotted on the Same Density Scale as that of Figure 3 for Experimental Design 1

No clear trend is evident in the density data plotted against LSE and scan speed. Generally, densities were lower overall for Experimental Design 2, compared to Experimental Design 1. A region of elevated density is present, caused largely by results for cases 20 and 24 . SEM images of specimens were examined to verify specimen build quality (on top edge of specimens, to view the in-fill quality), and surface roughness (on sides of specimens) was measured via Structured Light Scanning to correlate it with density. 
Highest Overall Density (95.85\%)

Plate9-Pos12, Case 20
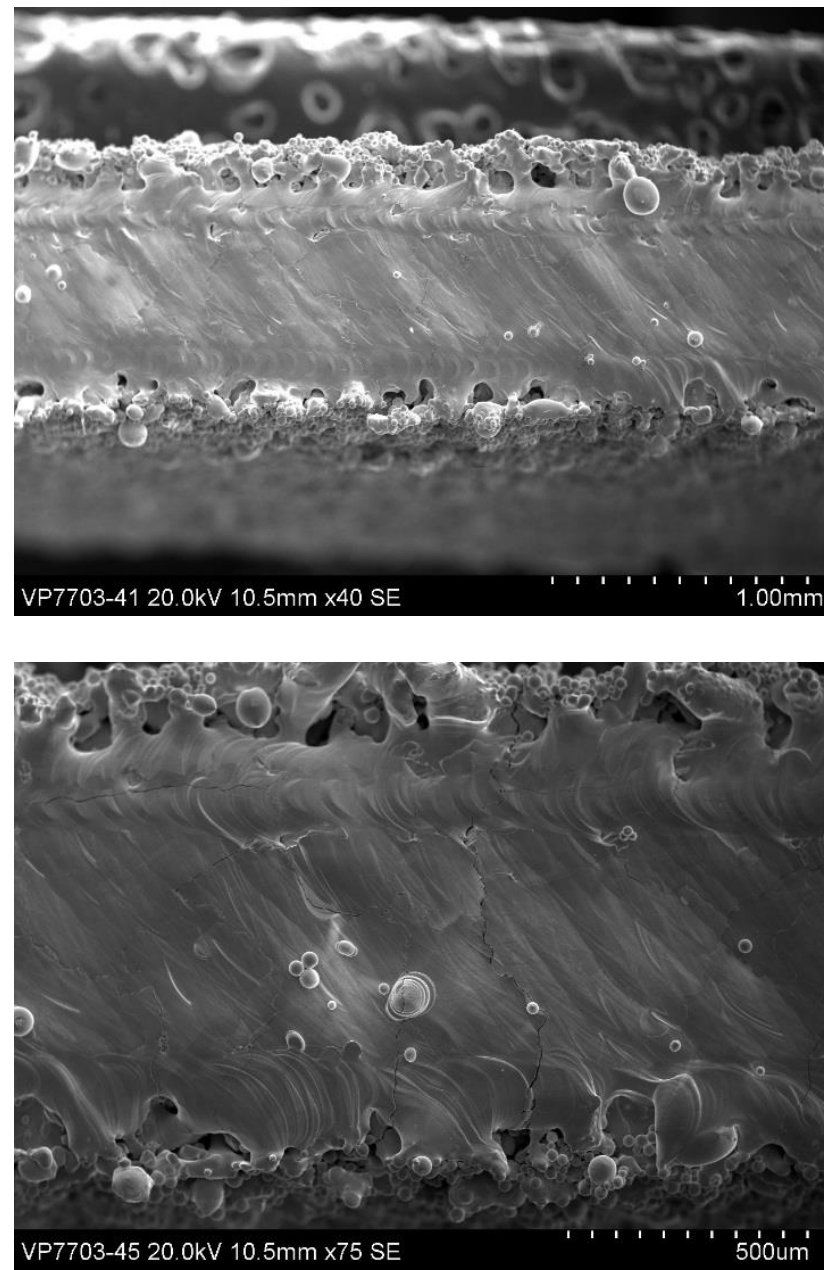

Lowest Case 20 (85.02\%)

Plate7-Pos20
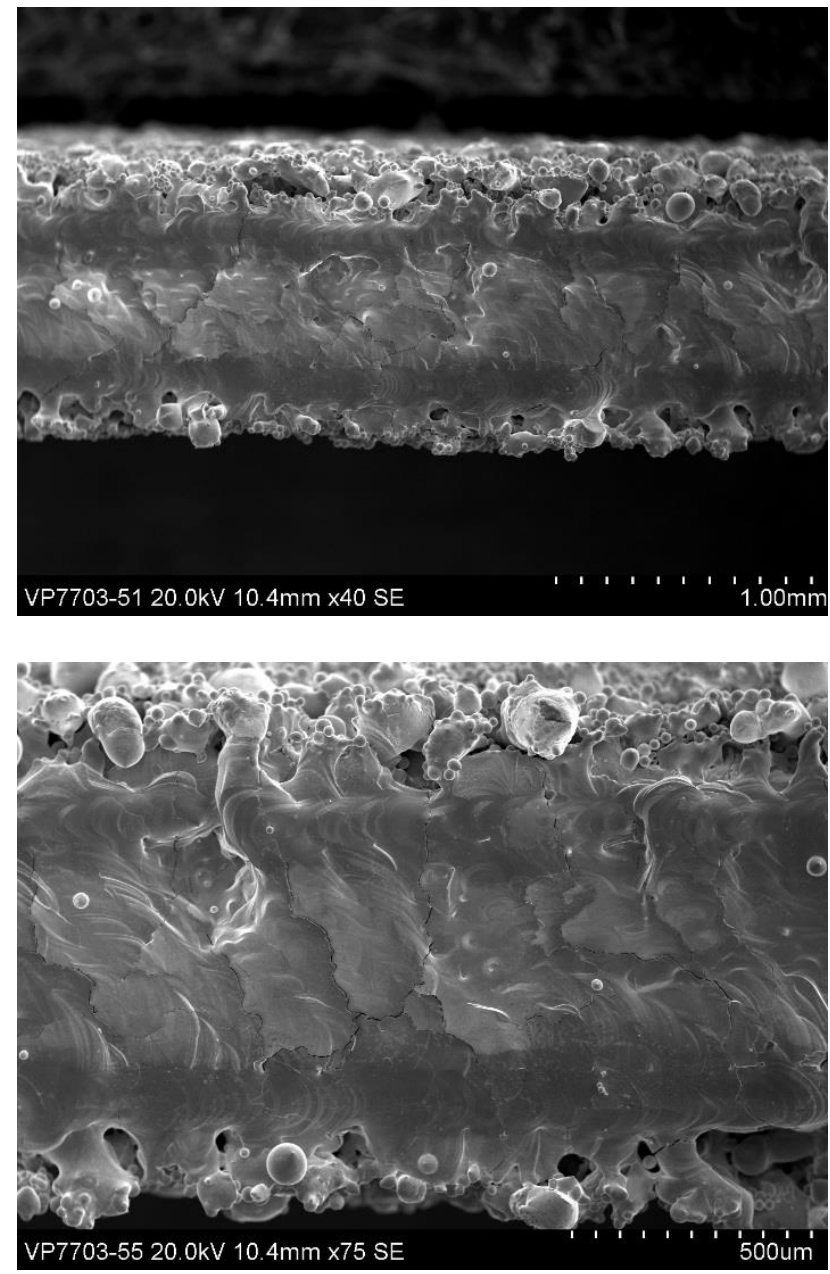

Figure 10: SEM Micrographs of the Highest Overall Density Specimen of Experimental Design 2 (Left), and the Lowest Density Replicate for the Same Case (Right)

Figure 10 displays SEM micrographs for the highest overall density specimen of Experimental Design 2, which was printed with Case 20 parameters, along with the lowest density replicate of Case 20 . There is a relatively large difference in density between the two specimens (approximately 10\%). The specimens were printed in different positions on different build plates. Micro-cracks are evident in the surface of even the higher quality specimen. 
Highest Overall Density (95.85\%)

Plate9-Pos12, Case 20
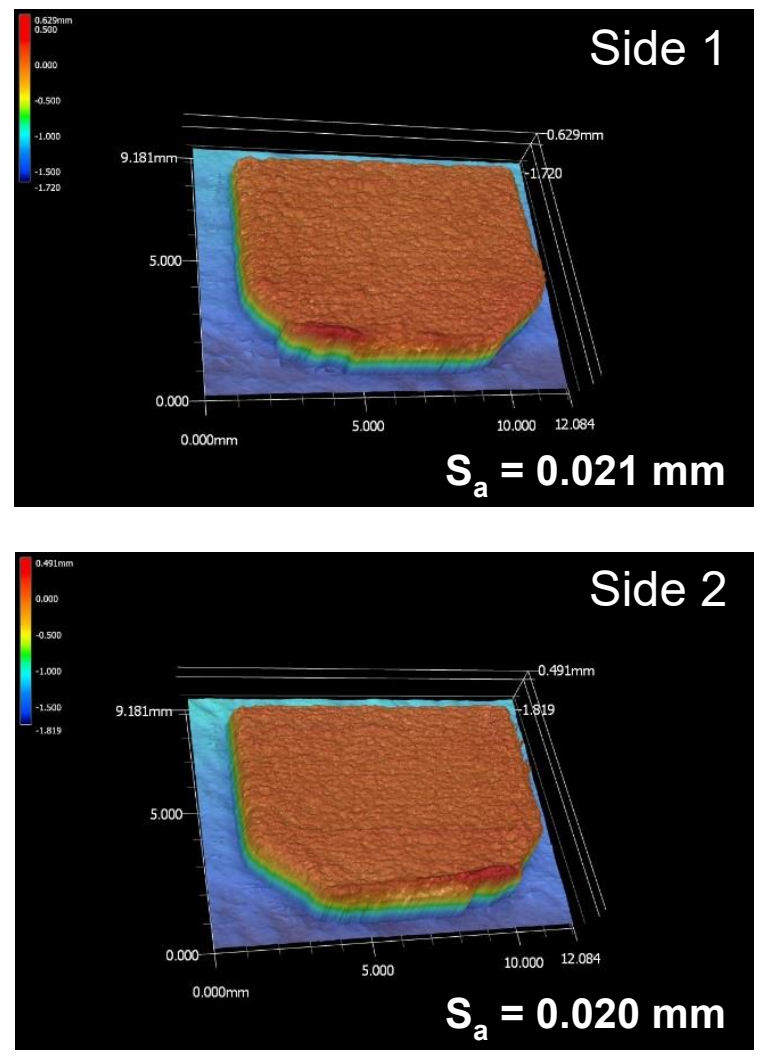

Lowest Case $20(85.02 \%)$

Plate7-Pos20
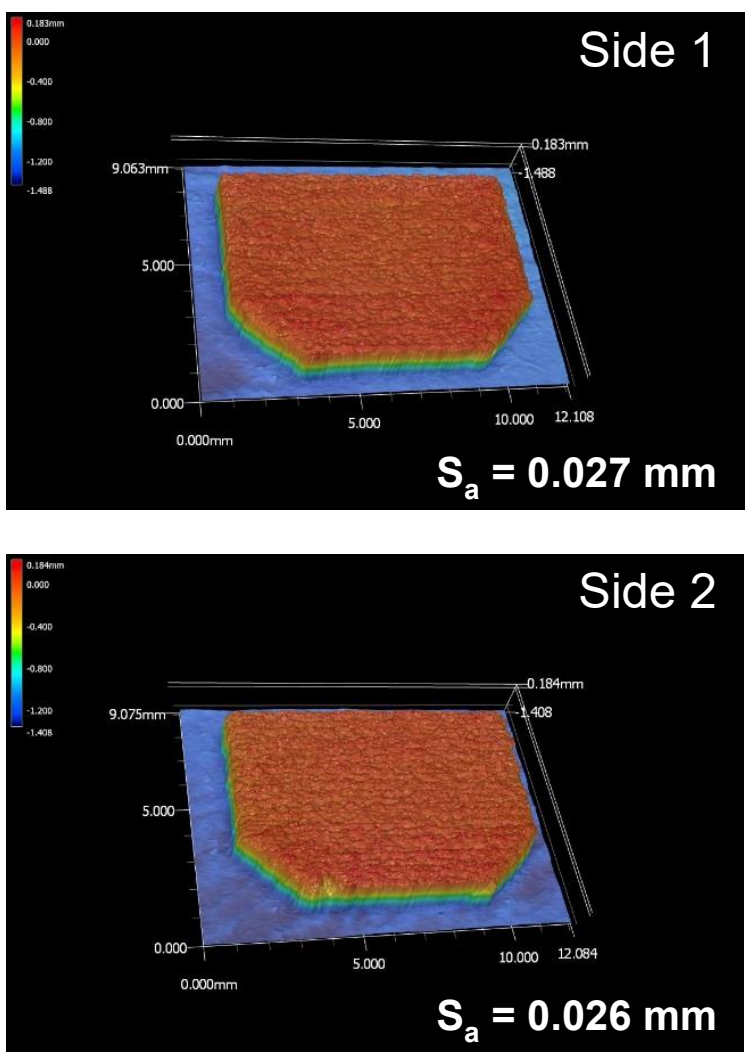

Figure 11: Structured Light Scanning of both sides of the Case 20 Specimens shown in Figure 10.

Structured Light Scanning revealed that for the case 20 specimens, one of which exhibited the highest overall density for Experimental Design 2, and the other, which had a relative density $10 \%$ lower, exhibited significantly different surface roughness characteristics. The lower density specimen had a surface roughness approximately $30 \%$ higher than that of the higher density specimen. 
Highest Plate 7 Density (92.84\%)

Plate7-Pos4, Case 13
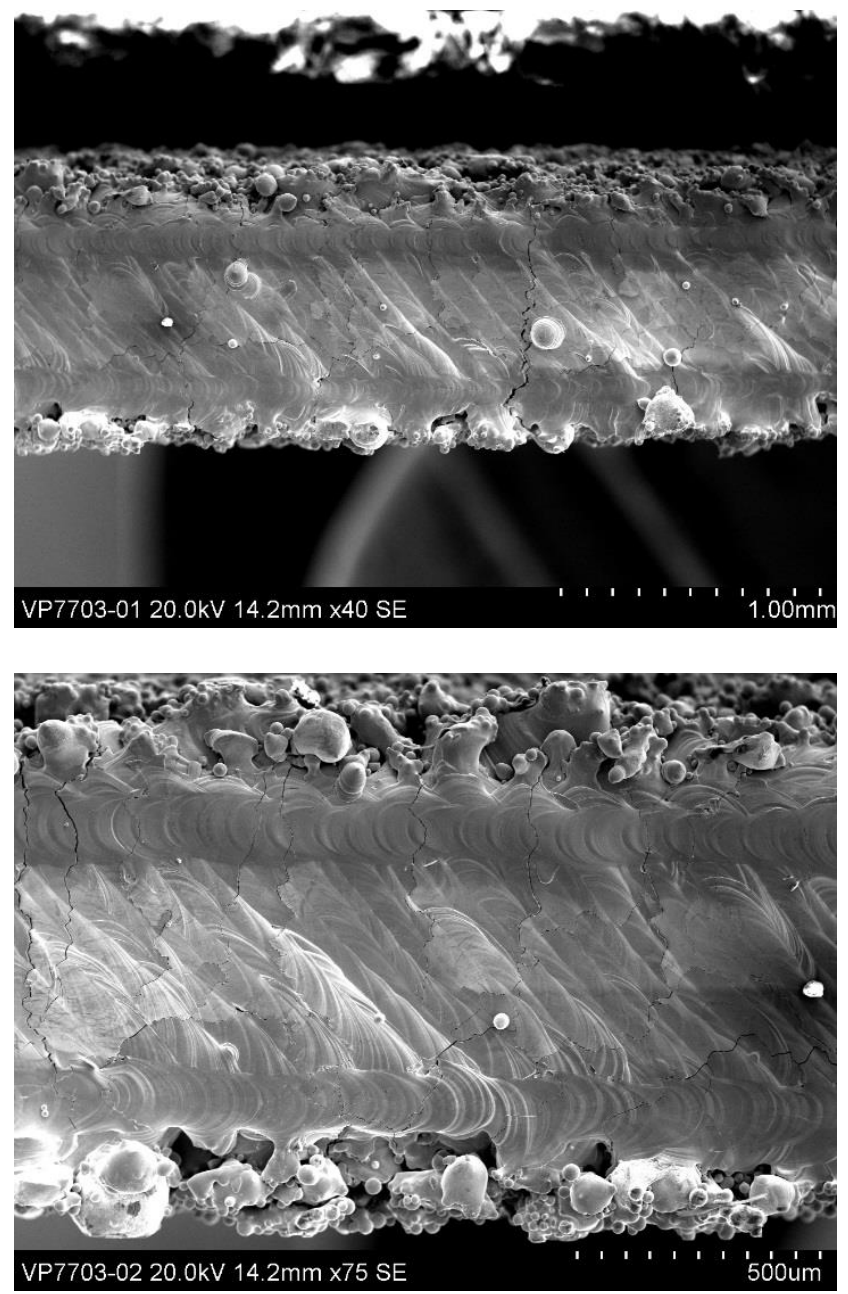

Lowest Overall Density (84.09\%)

Plate9-Pos19, Case 13
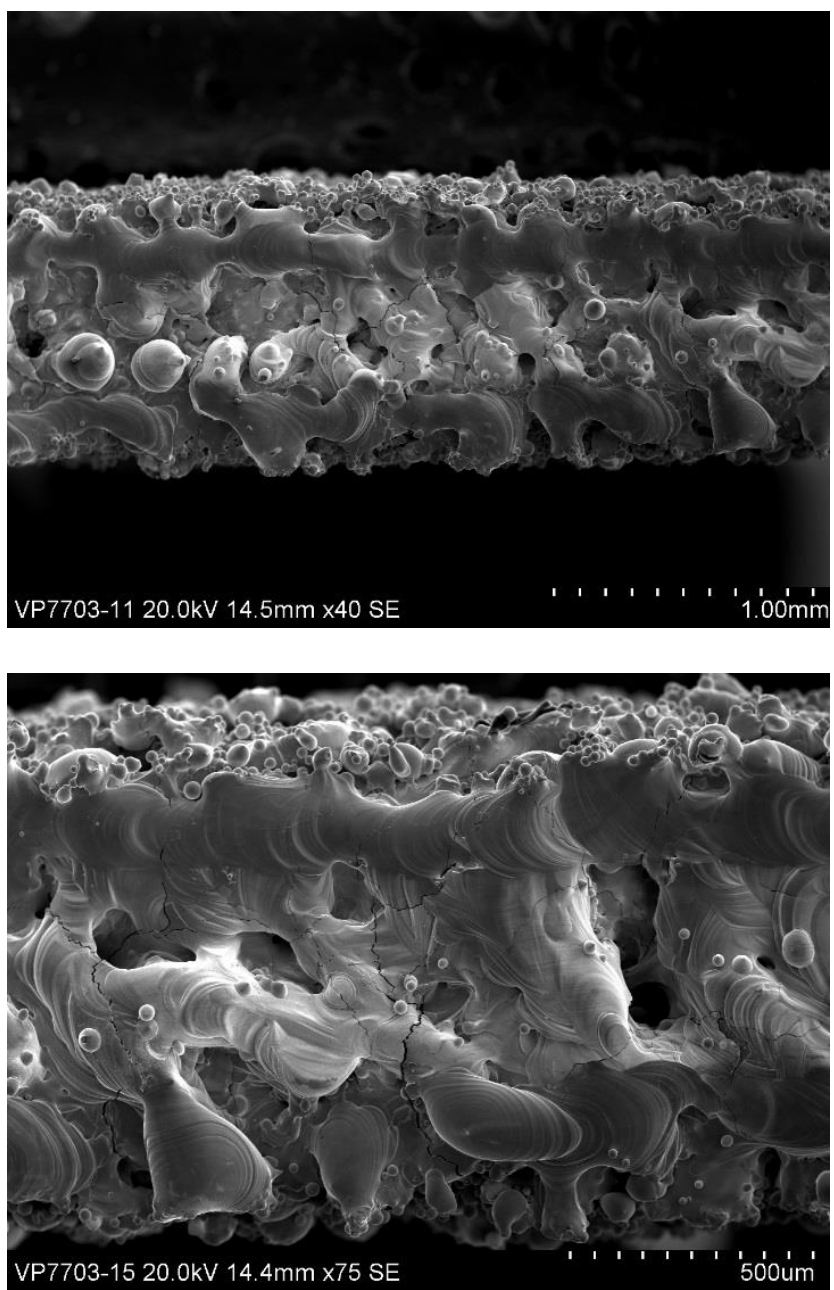

Figure 12: SEM Micrographs of the Lowest Overall Density Specimen of Experimental Design 2 (Right), and the Highest Plate 7 Density, a Replicate of the Lowest Density Case (Right)

SEM micrographs are shown in Figure 12 for two Case 13 specimens, one of which exhibited the lowest overall density for Experimental Design 2. The other Case 13 specimen exhibited the highest density for a Plate 7 specimen. Despite the two specimens being built with the same parameters, they exhibit significantly different qualities. Unfortunately, this juxtaposition demonstrates the level at which the plate no. and build position factors dominated the build parameter factors for the Experimental Design 2 study. Additional microscopy is available in the appendix of this report. 
The trend that was evident in Experimental Design 1 data (density plotted against laser specific energy and scan speed) was not replicated in Experimental Design 2. The signal the study attempted to characterize and map (density) was extremely noisy, driven in part by plate-to-plate variance and build position variance. Microscopy confirmed that there are significant within-case differences in build quality. The degree to which this is a problem is somewhat surprising (approximately a 10\% difference in density for the highest and lowest density values for Case 20, for example). However, surface roughness was confirmed as a method for monitoring build quality as it relates to density.

\section{BUILD POSITION AND SPECIAL PARAMETER STUDY}

Due to the significant influence of build position on the results of Experimental Design 2, a study was carried out to study the influence of build position alone on specimen quality. The effect of build position on the plate was examined by running plates filled with 20 replicates. This study also compared specimens made with only volume-fill passes (identified as Plate 4) to those with special parameters turned on (identified as Plate, 5 with up-skin, down-skin, border pass, and contour pass parameter modifications). These parameter modifications are depicted in Figure 13. Base parameters were selected as $400 \mathrm{~W}$ power, $300 \mu \mathrm{s}$ exposure time, $170 \mu \mathrm{m}$ hatch spacing, $63 \mu \mathrm{m}$ spot distance, and $30 \mu \mathrm{m}$ layer thickness.

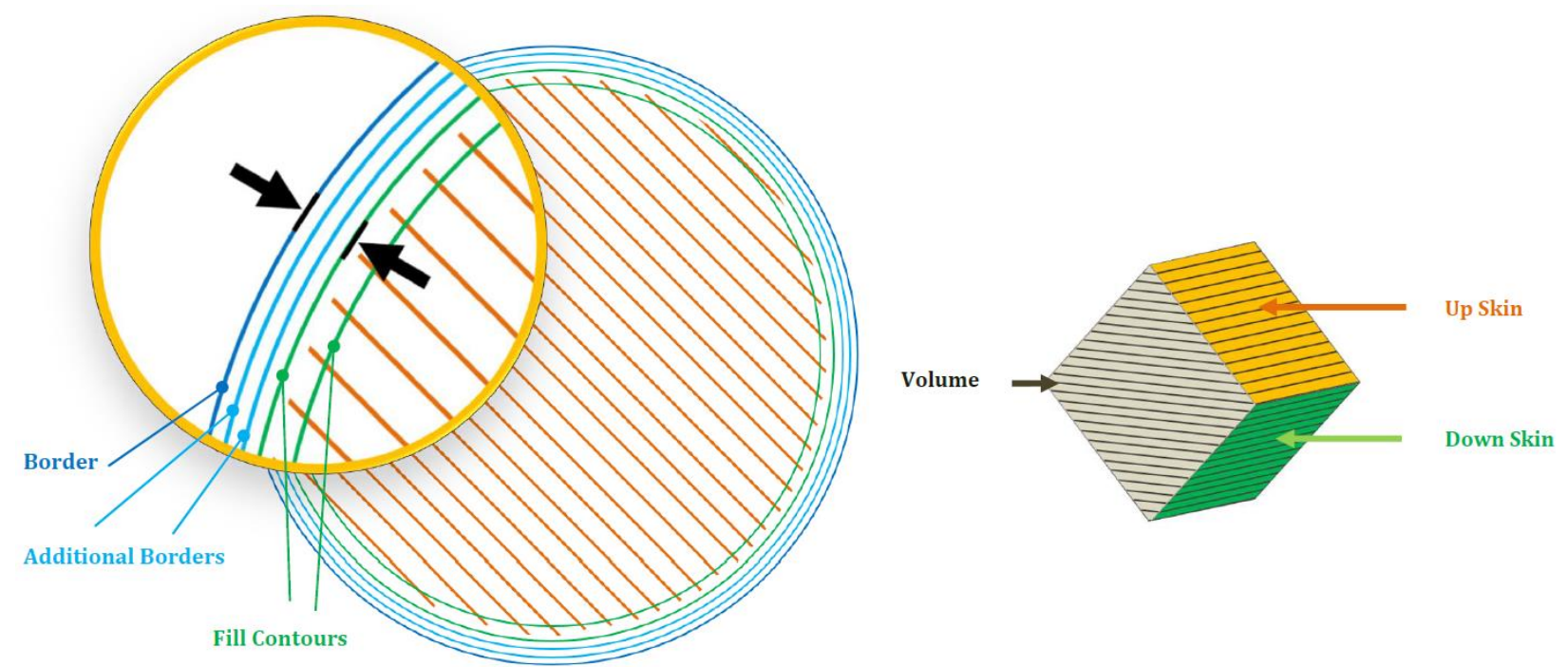

Figure 13: Geometries and Tool Paths for which Specific Build Parameters are often Selected in SLM to Improve Build Quality; Images Courtesy of Renishaw AMPD 
Results of the build position and special parameter study are shown in Figure 14 in the form of colormaps of specimen density and mass, plotted against actual build position on the plate.
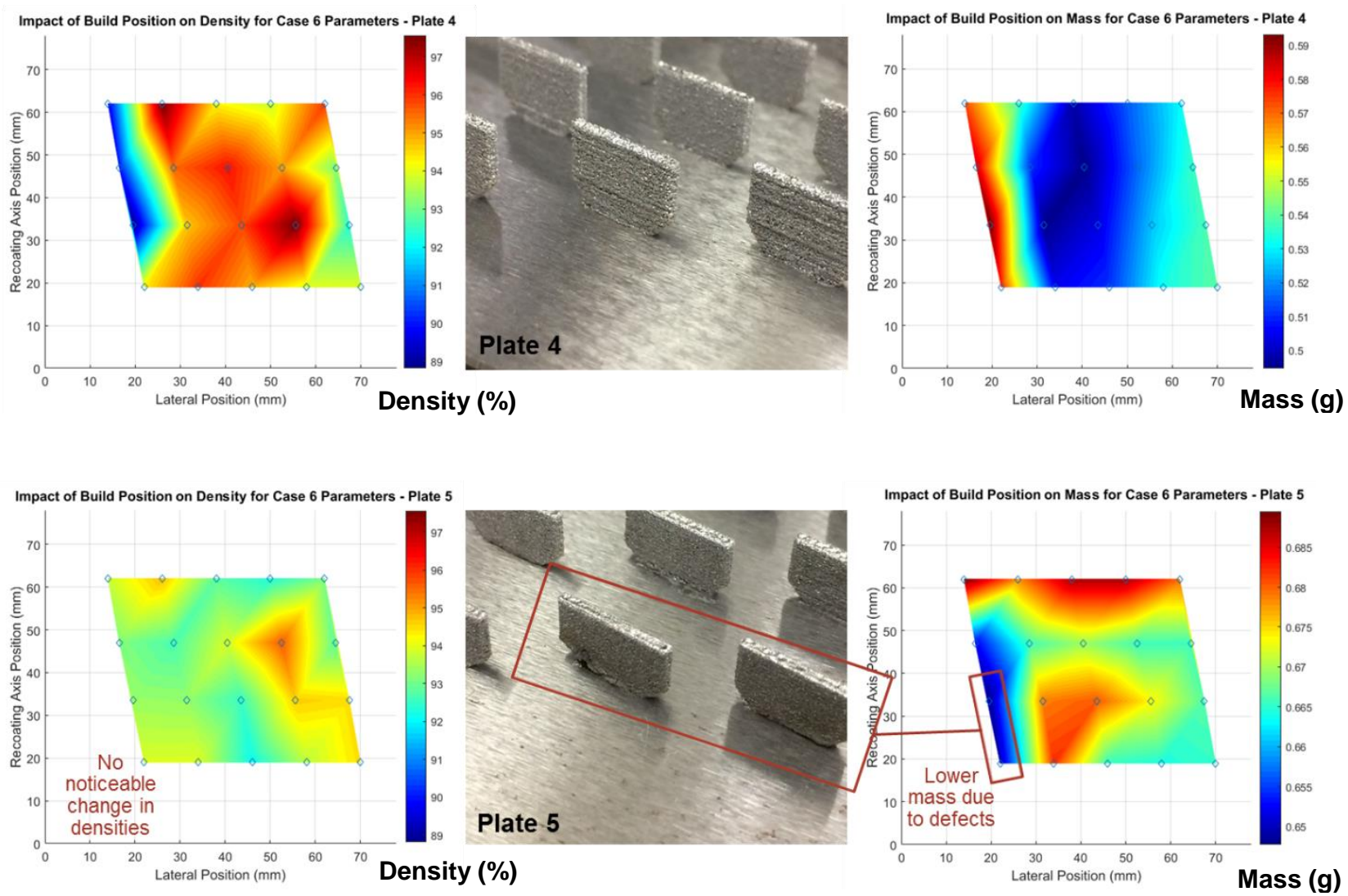

Figure 14: Results of the Build Position and Special Parameter Study

There are obvious anomalies that can show up in the data (both density and mass) that do not manifest as obvious flaws or features in the part upon visual inspection (see left side of Plate 4 in Figure 14), although perhaps an increased surface roughness is visible to the unaided eye on the lower density, higher mass parts; this was characterized with Structured Light Scanning, and the results are shown in Figure 15). Conversely, there can also be obvious flaws in parts (defects on the lower portion of some parts on Plate 5 , shown in Figure 14) that may not have signatures in the collected data. These parts do register as less massive, but do not have noticeably different densities. These differences due to build position may be driven largely by powder-recoating issues, although differences due to laser incidence angle with each part are inherent to the process as well [4]. 


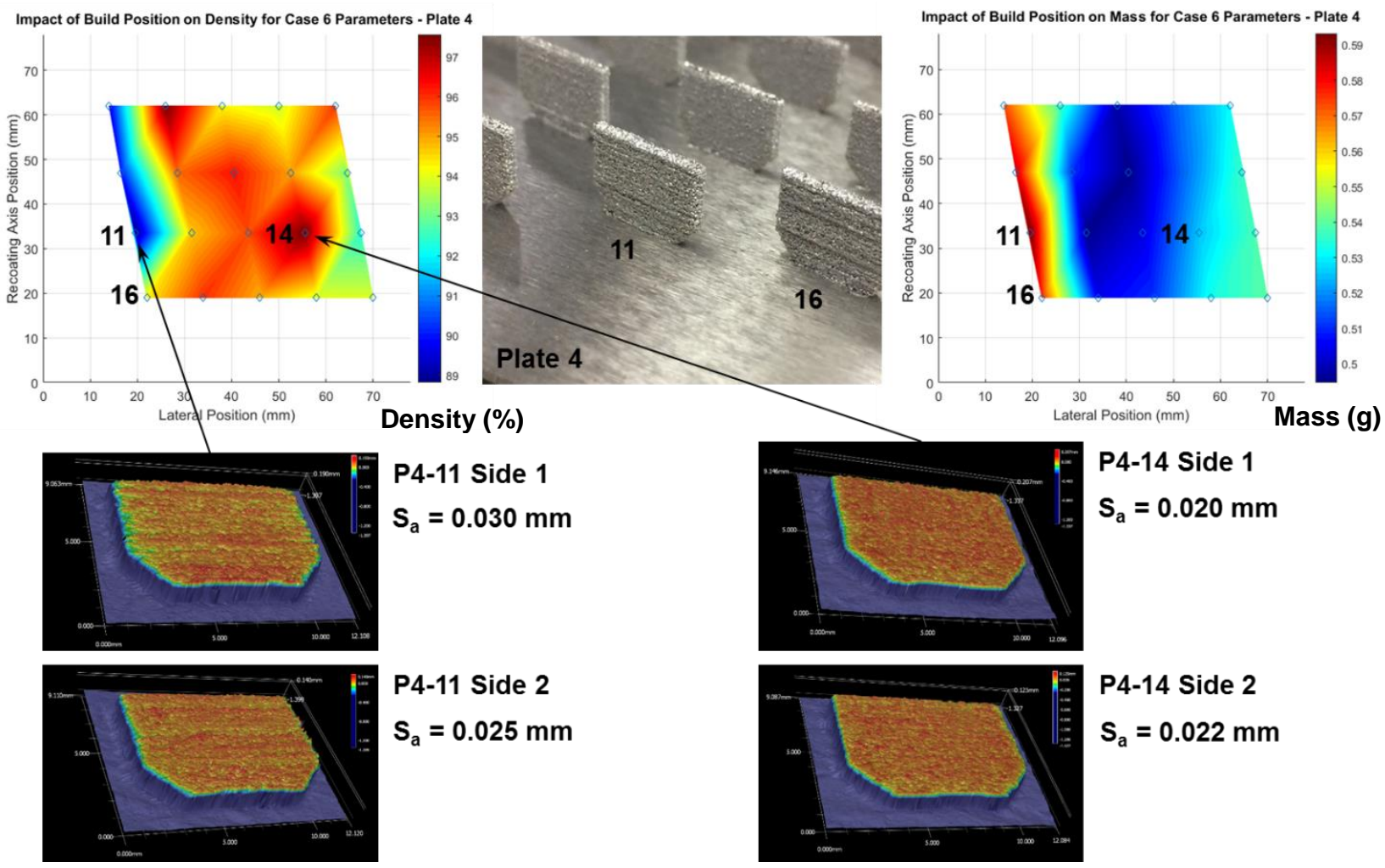

Figure 15: Roughness Characterization of Select Plate 4 Specimens Showing an Inverse Relationship Between Density and Roughness

Overall, densities were lower for parts with special parameters turned on (Plate 5) compared to those built with only volume-fill passes (Plate 4). However, special parameters may have an effect of making parts more robust or resilient to issues with powder-recoating.

\section{CONCLUSIONS}

Data from Experimental Design 1, the original study carried out to examine process parameters for SLM of Molybdenum, revealed intriguing trends in specimen density data when it was plotted against particular parameters, laser specific energy and scan speed. Experimental Design 2 attempted to replicate the trend while also expanding the density map to both higher and lower regions. Constraints on spot and hatch spacing were also intuitively self-imposed, based on the laser spot size, which helped to narrow the potential process window. Parameter modifications were also made based on observed changes 
in the performance of the Renishaw AM400 following the resolution of laser focus and cleanliness issues. As of the date of this report, replication of the trend in the plot of Experimental Design 1 density against laser specific energy and scan speed requires further effort to achieve. Throughout this work however, important relationships between density, mass, and surface finish did emerge. Parts were consistently produced with excellent closed densities and observations showed that reductions in overall density may be driven, as least in part, by surface finishes that have high porosity and additional powder bonded to the surface; parts with these surface finishes are typically more massive, pointing to an inverse relationship between density and mass for some of the sample sizes and operating conditions tested (not a universal relationship). Surface roughness was characterized through Structured Light Scanning. Two additional factors examined were 1) special parameters that are used for up-skin/down-skin conditions, border passes, and contour passes and 2) the effect of build position on outcomes for individual parts produced on the same plate. This work reinforced the importance of special parameters for part consistency and build outcomes like surface finish and dimensional accuracy. In terms of build position, while it is known that laser incidence angle varies from part-to-part on the same build plate, other challenges, such as inconsistencies in powder-recoating dynamics and variances in initial build plate flatness, likely impacted the results as well. 


\section{REFERENCES}

[1] J. Beuth, J. Fox, J. Gockel, C. Montgomery, R. Yang, H. Qiao, E. Soylemez, P. Reeseewatt, A. Anvari, S. Narra, N. Klingbeil, Process mapping for qualification across multiple direct metal additive manufacturing processes, Proceedings of the Solid Freeform Fabrication Symposium, 2013.

[2] F. Cardaropoli, V. Alfieri, F. Caiazzo, V. Sergi, Dimensional analysis for the definition of the influence of process parameters in selective laser melting of $\mathrm{Ti}-6 \mathrm{Al}-4 \mathrm{~V}$ alloy, Proceedings of the Institution of Mechanical Engineers, Part B: Journal of Engineering Manufacture, Vol 226, No 7, 2012.

[3] M. van Elsen, F. Al-Bender, J.P. Kruth, Application of dimensional analysis to selective laser melting, Rapid Prototyping Journal, Vol 14, No 1, 2008.

[4] S. Kleszczynski, A. Ladewig, K. Friedberger, J. zur Jacobsmühlen, D. Merhof, G. Witt, Dependency of surface roughness in parts from laser beam melting systems, Proceedings of the Solid Freeform Fabrication Symposium. 


\section{APPENDIX}

A. Additional Experimental Design 2 Microscopy

$2^{\text {nd }}$ Highest Overall Density $(94.97 \%)$ Plate9-Pos1, Case 24
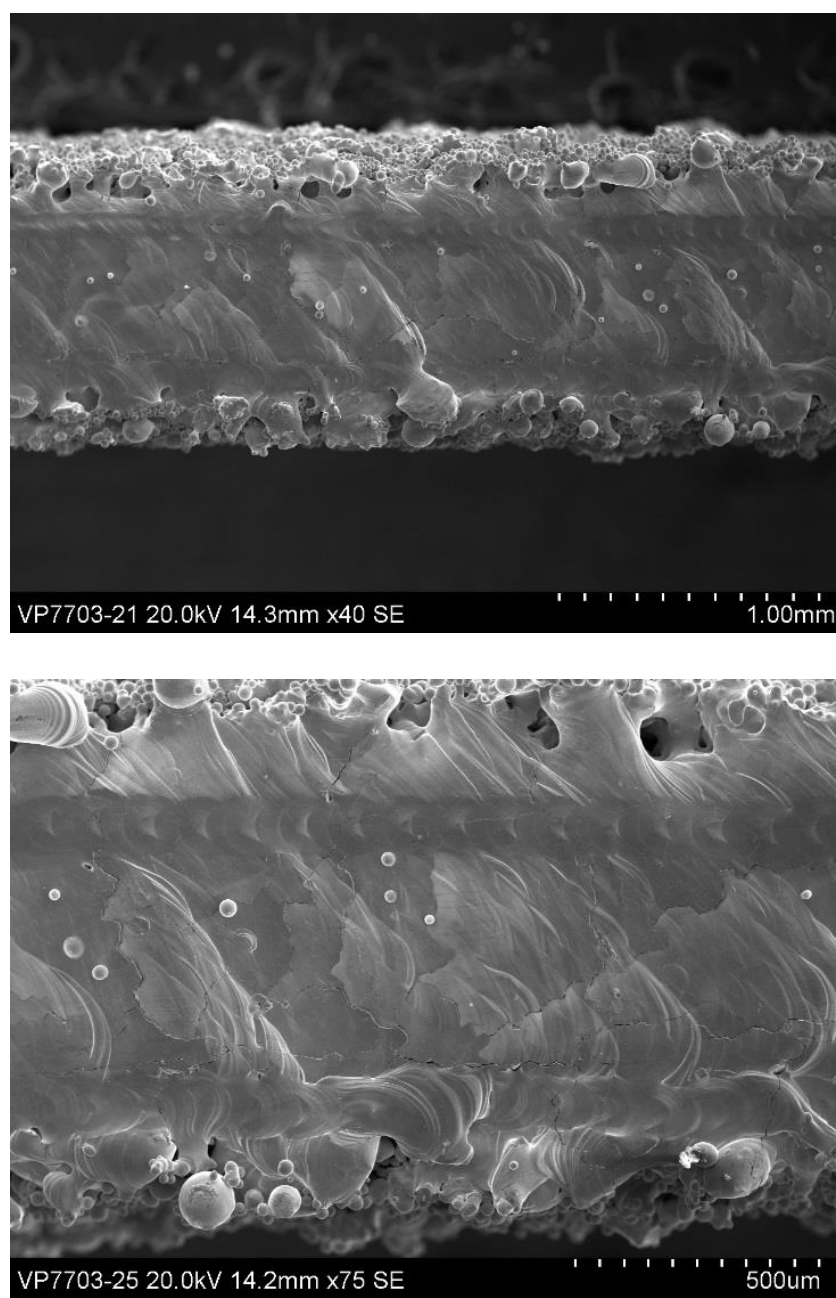

Lowest Case 24 (86.38\%) Plate7-Pos 15
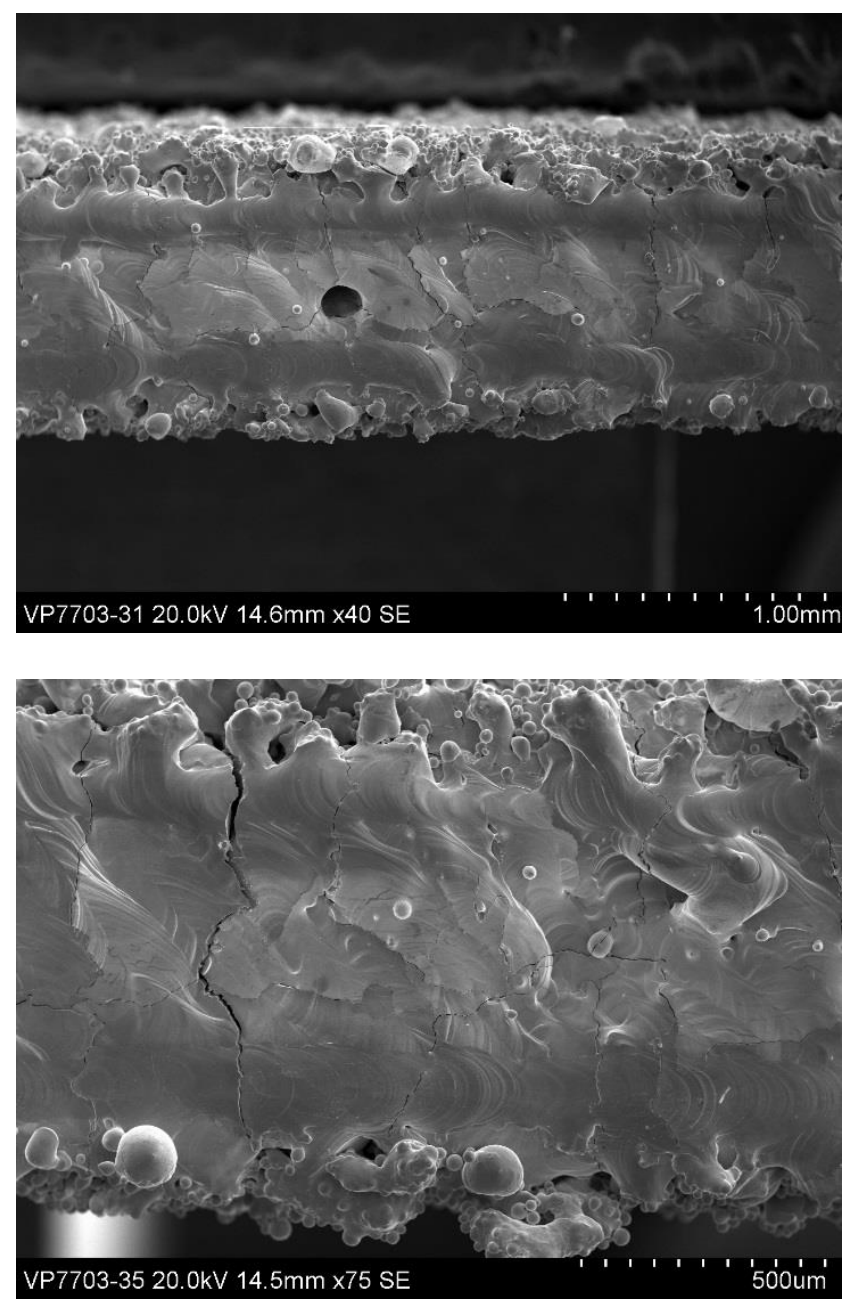
Highest Plate 8 Density (89.83\%) Plate8-Pos7, Case 24
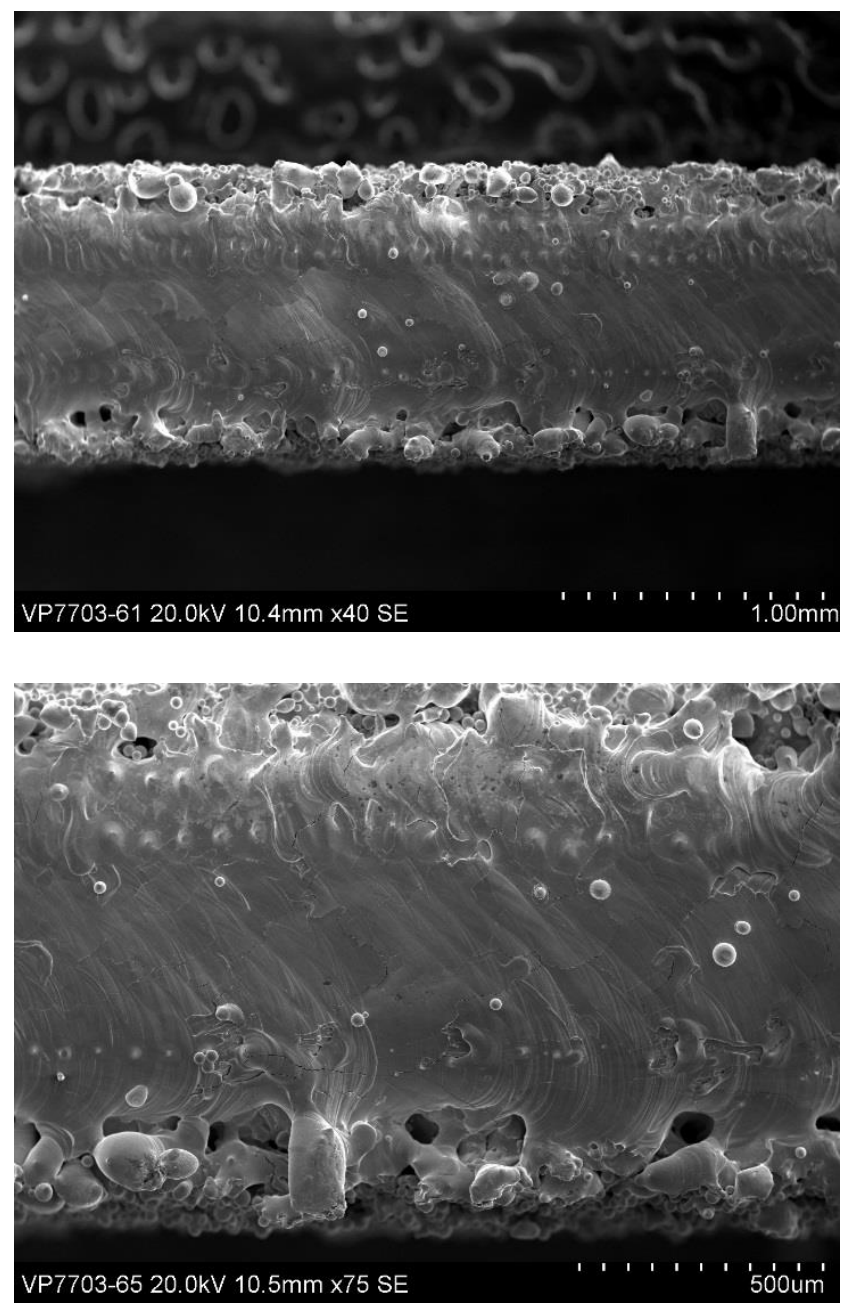

Lowest Plate 8 Density (85.88\%) Plate8-Pos20, Case 19
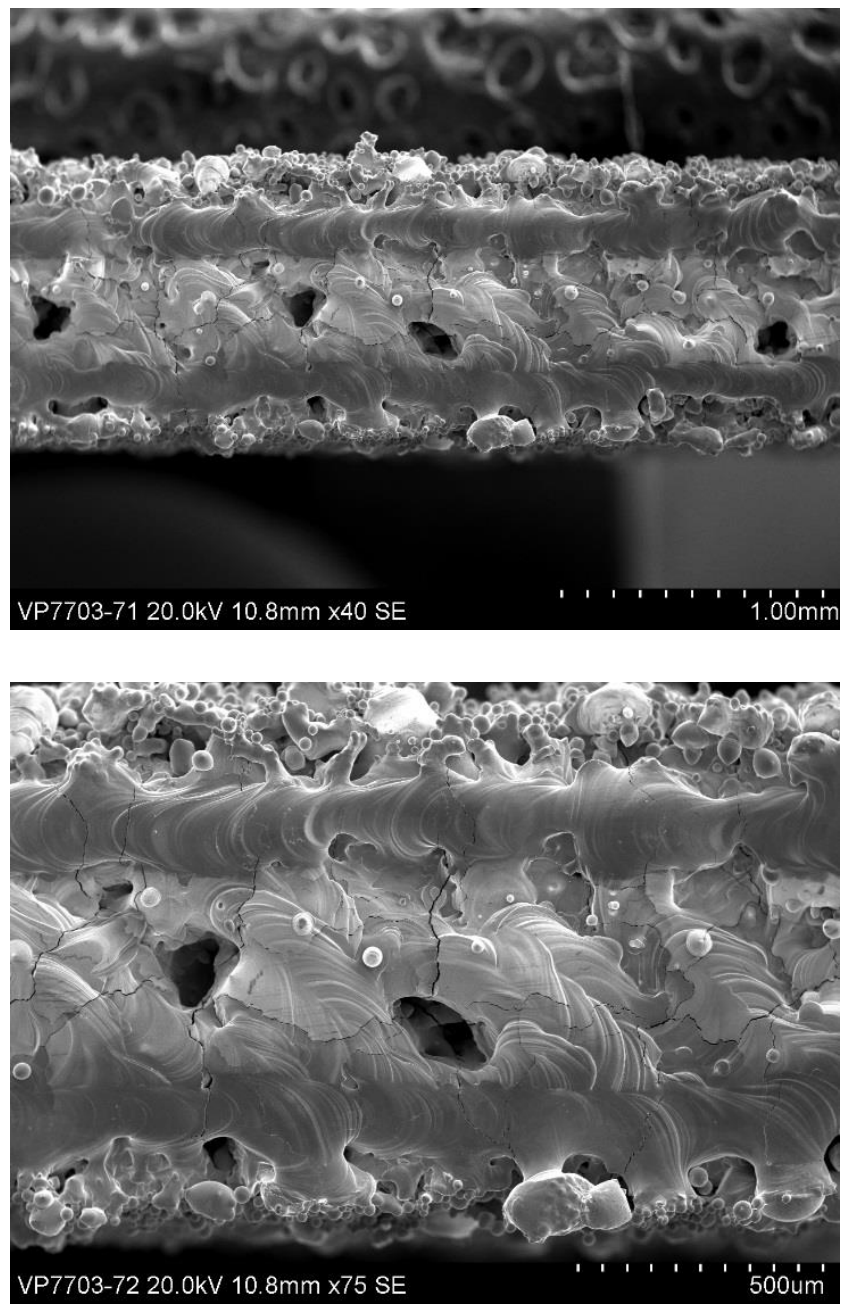